\title{
Association between theory of mind and mental state talk in preschoolers and later
} social competence and behaviour

Ana Luísa Barreto ${ }^{1}$, Ana Osório ${ }^{2}$, Joana Baptista $^{1}$, Pasco Fearon $^{3}$, \& Carla Martins ${ }^{1}$

${ }^{1}$ School of Psychology, University of Minho, Braga, Portugal

${ }^{2}$ Cognitive and Social Neuroscience Lab, Post-Graduate Program on Developmental

Disorders, Center for Biological and Health Sciences, Mackenzie Presbyterian

University, São Paulo, Brazil

${ }^{3}$ Faculty of Brain Sciences, University College of London, London, United Kingdom

Note: This research was supported by Grant COMPETE: FCOMP-01-0124-FEDER-

015504 from FCT (Fundação para a Ciência e Tecnologia) and the European Regional Development Fund (FEDER) through the European program COMPETE (Operational Programme for Competitiveness Factors) under the National Strategic Reference Framework (QREN) attributed to the research project titled “Children's socioemotional-cognitive school readiness: A longitudinal approach to its developmental course during preschool years" (PTDC/PSI-EDD/114527/2009), as well as the PhD funding to Ana Luísa Mendes Barreto (SFRH/BD/82326/2011).

Corresponding Author:

Carla Martins

Escola de Psicologia

Universidade do Minho

Campus de Gualtar 
Running Head: SOCIAL UNDERSTANDING AND LATER SOCIAL COMPETENCE

4710-057 Braga

cmartins@psi.uminho.pt 


\title{
Association between theory of mind and mental state talk in preschoolers and later social competence and behaviour
}

\begin{abstract}
This study had two primary aims: a) to investigate the concurrent links between preschool-aged children's theory of mind (ToM) and mental state talk at 55 months and b) to examine the longitudinal associations between preschool-aged children's social understanding, as indicated by their ToM, and mental references, and their later social competence and behaviour at 69 months. Participants included 73 children and their mothers. ToM was assessed using a battery that consisted of six standardized tasks, and social competence and behaviour were assessed via teacher ratings. We observed an association between children's ToM and their mental state talk, specifically regarding cognition references during interactions with their mothers. Moreover, both children's theory of mind and mental references were longitudinally related to social competence and behaviour but only in girls. Our results support that ToM, which was assessed using false belief tasks, and the child's tendencies to refer to mental states during everyday interactions are two important related markers of children's social understanding and that both are linked to children's social competence and behaviour. The importance of considering gender-specific effects when investigating children's social cognition is also highlighted.
\end{abstract}

Keywords: theory of mind; mental state talk; social competence; preschoolers 
Running Head: SOCIAL UNDERSTANDING AND LATER SOCIAL COMPETENCE

Association between theory of mind and mental state talk in preschoolers and later social competence and behaviour

During the preschool years, children go through major changes in their social understanding and in their understanding of their own minds, as well as the minds of others. In fact, between the age of 3 to 5 years, children typically develop an explicit theory of mind (ToM), the ability to attribute mental states (e.g., desires, beliefs, emotions) to oneself and to others, and the ability to understand and anticipate behaviour based on those mental states (Astington \& Barriault, 2001). During this time, children start to understand false beliefs, or the notion that two people can have distinct beliefs about the same situation and that those beliefs could even be false. Thus, false belief understanding is considered an important marker of ToM acquisition, and when children start passing false belief tasks, they are said to understand the representational nature of beliefs and therefore to have developed a representational ToM (Wellman, Cross, \& Watson, 2001). Accordingly, most studies on ToM have measured children's understanding of the mind using false belief tasks, in which they are presented with short stories and are asked to explain or to predict a character's behaviour based on the inferred mental states of the character (Wellman et al., 2001; Wellman \& Liu, 2004). Research findings show that a portion of children display a relatively earlier understanding of the mind and that these inter-individual differences appear to be related to several aspects of children's social context, particularly family characteristics and interaction patterns, which highlights the role of these aspects in promoting children's ToM development (Carpendale \& Lewis, 2004). For example, children who have siblings (e.g., McAllister \& Peterson, 2007; Ruffman, Perner, \& Parkin, 1999), children who display a secure attachment (e.g., Repacholi \& Trapolini, 2004; Symons \& 
Clark, 2000), and children whose parents use specific disciplinary strategies (e.g., Hughes, Deater-Deckard, \& Cutting, 1999; Ruffman et al., 1999) show better performance on ToM tasks. Additionally, an extensive body of research has focused on the role of mental state talk, specifically parents' use of mind-related words, in promoting children's ToM abilities. Hence, researchers have consistently shown that parents who make more references to mental states when interacting and talking with their offspring have children who perform better on ToM tasks (e.g., Meins, Fernyhough, Arnott, Leekam, \& de Rosnay, 2013; Ruffman, Slade, \& Crowe, 2002; Ruffman, Slade, Devitt, \& Crowe, 2006; Symons, Peterson, Slaughter, Roche, \& Doyle, 2005). While these studies have mostly examined the importance of parents' mental references, other studies have focused on the child's tendency to refer to mental states spontaneously, which is considered to be another important marker of children's growing understanding of their own minds and the minds of others (e.g., Bartsch \& Wellman, 1995; Bretherton \& Beeghly, 1982; Osório, Meins, Martins, Martins, \& Soares, 2012). In fact, previous research carried out by Taumoepeau and Ruffman (2006) has also shown correlations between both the mother's mental state talk and the child's use of mental references and subsequent performance on emotional tasks, which provides support to the idea that children's talk about mental states is indeed tapping into their basic social understanding.

Furthermore, while children's performance on false belief tasks continues to be used as an index of their underlying understanding of the mind, studies have revealed that even younger children, who are not expected to succeed on false belief tasks, show some understanding of mental states during their everyday social interactions (Dunn, 1988, 1991). Therefore, it is possible that other manifestations of children's understanding of the mind, such as their tendency to refer to mental states when 
Running Head: SOCIAL UNDERSTANDING AND LATER SOCIAL COMPETENCE

interacting with others, can provide additional, more naturalistic and possibly even more accurate index of children's social understanding (Hughes, Lecce, \& Wilson, 2007). Accordingly, a number of studies have sought to assess children's understanding of the mind using more naturalistic paradigms by looking at children's spontaneous use of mind-related references, both in interactional and non-interactional contexts. For example, our research showed that 3-year-old children's use of desire-related terms during pretend play with their mothers was linked to their ability to incorporate an experimenter's symbolic suggestions - a social-cognitive ability that is thought to precede ToM (Osório et al., 2012). In addition, prior research has suggested links between children's performance on ToM tasks and their use of mental references, thereby providing evidence for the idea that mental state talk is related to the development of social understanding (Symons, 2004). In this sense, several studies have shown that children who display better ToM abilities employ more references to mental states during interactions with their parents (Ensor \& Hughes, 2008; Nielsen \& Dissanayake, 2000; Ruffman et al., 2006), siblings and friends (Brown, DonelanMcCall, \& Dunn, 1996; Hughes \& Dunn, 1998; Hughes et al., 2007; Hughes, Ensor, \& Marks, 2011). Symons and colleagues (2005) found similar results during a narrative task, when assessing children's spontaneous use of mental references in a noninteractional context in response to a set of photographs that they were presented with; however, the authors did not find the same association when children's mental references were assessed during dyadic shared book-reading interactions with their parents. Additionally, in a recent study, Meins and colleagues (Meins et al., 2013) showed associations between children's ToM abilities and their use of mental state terms, as reported by their mothers in a questionnaire. However, despite the vast amount of literature documenting this relationship, only the latter study examined ToM using a 
battery of tasks that were designed to assess children's understanding of distinct mental concepts that compose ToM development.

The present study aims to extend previous research by examining the concurrent associations between children's performance on a battery of ToM tasks and their use of mental state references during mother-child shared book-reading interactions, while also investigating the longitudinal relationships between these two indices of preschool children's social understanding and their social competence and behaviour later in life before beginning school.

While many researchers focused on individual differences relating to ToM and their association with variables from children's social context, several studies have also looked at the links between children's ToM abilities and other social competencies, yielding mixed results. While several authors found results suggesting that children who displayed better performance on ToM tasks were rated by their teachers as displaying more prosocial and socially competent behaviours, both concurrently (e.g., Capage \& Watson, 2001; Lalonde \& Chandler, 1995; Weimer \& Guajardo, 2005) and longitudinally (e.g., Razza \& Blair, 2009), others did not observe this relationship (e.g., Garner, Curenton, \& Taylor, 2005). Furthermore, findings from other studies have suggested concurrent associations between preschoolers' ToM and their social competence as reported by teachers, depending on the gender of the children. For example, Walker (2005) found that 3- to 5-year-old girls who showed a more advanced ToM were rated by their teachers as displaying more prosocial behaviours. Conversely, boys who performed better on ToM tasks were rated by their teachers as showing more aggressive and disruptive behaviours and less shy and withdrawn behaviours. Similar results were reported by Razza and Blair (2003), who conducted a study on 4-year-old children from low-income backgrounds and found a relationship between ToM and 
social competence in girls but not in boys. To the best of our knowledge, these two studies were the only ones that looked at gender differences when examining the link between ToM and social competence in preschoolers. However, since both studies were cross-sectional, only concurrent associations were explored; it is our aim to investigate the existence of longitudinal associations between ToM and social competence and behaviour while also exploring possible gender differences in this relationship.

Furthermore, while several studies examined the links between ToM abilities and social competence in preschoolers, very few seem to have investigated the associations between children's spontaneous displays of social understanding, such as references to mental states, and their social competence. In one exception, Garner, Dunsmore and Southam-Gerrow (2008) examined mother-child discourse regarding emotions in a book-reading task and found that preschool children who provided more emotional explanations showed more prosocial behaviour, as observed during children's interactions with their peers. In addition, a recent study that was conducted on older, school-aged children also examined the links between both children's ToM and their use of mental references and their teacher-rated social adjustment (Longobardi, Spataro, \& Rossi-Arnaud, 2015). The authors found that only children's references to mental states were concurrently related to their social adjustment, specifically with emotional instability and aggressiveness. Moreover, ToM and mental state talk were not associated, which is consistent with other research on children in this age group (e.g., Meins, Fernyhough, Johnson, \& Lidstone, 2006).

However, Garner et al. (2008) focused specifically on concurrent discourse surrounding emotions only and Longobardi and colleagues considered children's general references to mental states only; thus, they did not examine the associations between references to specific mental states, such as cognitions or desires, and 
Running Head: SOCIAL UNDERSTANDING AND LATER SOCIAL COMPETENCE

children's behaviour. Also of importance is that these studies were not aimed at exploring the possible gender-specific effects on the relationships between children's discourse and ToM, and social behaviour, which was one of the goals of our study.

In summary, this paper has two main aims: a) to investigate the concurrent associations between children's ToM and their use of mental state references during mother-child shared book-reading interactions; and b) to examine the longitudinal associations between preschool children's social understanding and ToM, and their use of mental references and their teacher-rated social competence and behaviour later in life. Additionally, given that prior research suggests that the link between children's ToM and social competence may vary according to the children's gender (Razza \& Blair, 2003; Walker, 2005), we investigated the association between children's social understanding and social competence separately by gender. Finally, since we examined children's use of mental references during interactions with their mothers, we investigated the relationship between the children's and the mothers' discourse during those interactions in order to control for any potential associations between the two. Similarly, we also examined the associations between children's ToM and mental references and other control variables, such as their mothers' education level, the children's age at the time of the assessment and the children's verbal ability.

\section{Method}

\section{Participants}

Seventy-three mother-child dyads were recruited from child-care centres in northern Portugal for participation in a broader longitudinal study on the association between children's socio-cognitive and socio-emotional competencies and their readiness for school. Children (38 boys, $52.1 \%$ male) were assessed at two time points: 
Running Head: SOCIAL UNDERSTANDING AND LATER SOCIAL COMPETENCE

once at 4 1/2 years of age (Time 1, T1) and once approximately one year later (Time 2, T2). At T1, children were aged between 53 and 60 months $(M=55.01, S D=1.55$; for girls, $M=54.74, S D=1.20$; for boys, $M=55.26, S D=1.80$ ), and the majority were first-born children $(61.6 \% ; n=45)$. The primary caregivers were mostly mothers. At $\mathrm{T} 2$, children were aged 69.53 months on average $(S D=3.01$, range $65-76$ months; for girls, $M=68.91, S D=3.26$; for boys, $M=70.11, S D=2.67$ ).

At T1, mothers were between 26 and 46 years old $(M=36.89, S D=3.64)$. Regarding education level, most mothers $(68.5 \% ; n=50)$ had completed a university degree, 11 mothers $(15.1 \%)$ had a masters or doctoral degree, and the remaining 12 mothers $(16.4 \%)$ had completed up to 12 years of formal education. All participants spoke Portuguese as their native language, and all data collection was performed in Portuguese.

\section{Procedure}

At T1, children visited the laboratory twice. During the first session, the mothers were given information about the purpose of the study, as well as details on the included procedures, and later provided written informed consent. Next, the mothers and the children were videotaped during a wordless picture-book reading task in order to assess the mothers' and the children's use of mental references. The children's ToM was assessed during the second session using a battery of six standardized tasks. The children's verbal ability was assessed using the Peabody Picture Vocabulary Test Revised (PPVT-R, Dunn \& Dunn, 1981).

At T2, the children were visited twice in their preschool. During one of the visits, the children's social competence was assessed through teacher report using the Portuguese version of the Social Competence and Behaviour Evaluation Scale (LaFreniere \& Dumas, 1996; Portuguese version, Santos \& Veríssimo, 2008). 


\section{Measures}

Children's ToM. Children's ToM was assessed using a set of six standardized tasks, namely, four tasks from a ToM scale for preschoolers (Wellman \& Liu, 2004): (i) Diverse Beliefs, (ii) Knowledge Access, (iii) Unexpected Contents False Belief and (iv) Explicit False Belief; and two additional false belief tasks (Hughes, Adlam, Happé, Jackson, Taylor, \& Caspi, 2000): (v) Unexpected Contents II and (vi) Unexpected Location.

a) The Diverse Beliefs task required children to be able to understand that a character had a different belief from their own and to predict the character's behaviour based on that different belief. During the task, children are presented with a character named Sarah and are told that Sarah wants to find her cat; next, the children are asked whether they think Sarah's cat is in the garage or in the tree. Depending on the child's answer to this question, the experimenter then says that Sarah thinks that the cat is actually in the location that the child did not pick. Next, children are asked where they think Sarah is going to look for her cat.

b) The Knowledge Access task assessed children's understanding that knowledge depends on having access to information. Children are shown a wooden box and asked what they think is inside it. The experimenter then shows children that there is a ball inside the box. Children are then presented with a character named Bia, who has never seen what is inside the box, and asked whether Bia knows what is inside the box and, as a control question, whether she saw what was inside the box.

c) In the Unexpected Contents task, children were expected to predict that a character would think that there were potato chips inside of a box that is labelled 'potato chips' based on the appearance of the box, rather than on the actual contents of the box 
(a toy bear), which the children had already seen. Children are shown a Pringles box and asked what they think is inside it. After being shown that there is a toy bear inside the box, they are presented with a character named John and are told that John has never seen what is inside the box, and they are asked to predict what John thinks is inside the box. As control questions, children are asked what is really inside the box and whether John saw what was inside the box.

d) The Explicit False Belief task aimed to assess children's ability to predict a character's behaviour when searching for a pair of gloves based on the character's false belief, rather than on the children's own knowledge. Children are presented with an illustrated card showing a wardrobe and a backpack and are told that a character named James wants to find his gloves. Next, they are told that the gloves are really in the backpack, but that James thinks they are in the wardrobe. Children are subsequently asked to predict where James is going to look for his gloves and, as a control question, where the gloves really are.

e) The Unexpected Contents II task assessed children's ability to recall their own false belief when first asked what is inside a kinder chocolate box, after being shown its actual contents (pencils). Children are presented with a kinder chocolate box, and asked what they think is inside it. After being shown that there are pencils inside the box, children are asked a control question about what is really inside the box and what they thought was inside the box before looking inside.

f) Finally, the Unexpected Location task required children to predict a character's behaviour when looking for his apple based on his false belief, since the character had no knowledge that the location of his apple had changed. Children are shown illustrated cards that present a story, in which one character, named Joana, 
changes the location of an apple, while another character, named Andrew, is not looking. As control questions, children are asked where the apple really is and where it was originally; next, the key question is asked about where Andrew is going to look for his apple.

The first two tasks are the easiest and were conducted in a fixed order; the order of the remaining four tasks was counterbalanced in order to avoid contamination of data between the tasks. All of the tasks were coded in terms of success or failure and to succeed in each of the tasks, the children had to answer both the control and the key questions correctly. Twenty-four (31\%) of the videotapes were randomly selected and coded by a second blind coder. Interrater reliability was calculated using Cohen's kappa and ranged between .88 (for the Unexpected Contents II task) and 1.00 (for all other tasks). A composite ToM measure was calculated, consisting of the sum of the child's scores on all six tasks; thus, the range of scores was from 0 to 6 . Cronbach's alpha for this composite measure was .55 , which is consistent with reliability coefficients that have been reported in previous studies that used similar ToM measures (Astington \& Jenkins, 1999; Meins et al., 2002, 2013).

Mental state references. Mothers and children were videotaped during a shared book-reading task, using one of two wordless picture books: Frog where are you? (Mayer, 1969) or Frog on his own (Mayer, 1992). Mothers were asked to tell the story to their children, based on the book's pictures. Their interactions were videotaped, transcribed and then coded in order to access both the mothers' and the children's use of mind-related words. If present, the following aspects were coded a) desires, e.g., like, dislike, want, b) cognitions, e.g., think, know, imagine, and c) emotions, e.g., happy, sad, angry. A total of all of the mental references was also computed, adding the 
references to desires, cognitions and emotions. As in previous studies, utterances that served only as conversational devices (e.g., "I don't know"), or that were repetitions of one's own utterances or someone else's utterances were not coded (Jenkins, Turrell, Kogushi, Lollis, \& Ross, 2003; Ruffman et al., 2002). To control for differences in verbosity, both the mothers' and the children's mental state references were calculated as proportions of the total number of words that were used during the interaction. Interrater reliability was assessed by computing the intraclass correlation coefficients (rICC) for $21 \%(n=16)$ of the mother-child interactions, which were independently coded by two trained raters. Intraclass correlations for the three types of mental references ranged between $r_{\mathrm{ICC}}=.89$ and $r_{\mathrm{ICC}}=.99$ for mothers and were $r_{\mathrm{ICC}}=1$ for the three types of mental references for children.

Children's verbal ability. Children's verbal ability was assessed using the Peabody Picture Vocabulary Test - Revised (PPVT-R, Dunn \& Dunn, 1981). Children were orally presented with words and asked to choose from a set of four pictures concerning which one corresponded to the word they had previously heard. The coding consisted of subtracting the total number of errors from the highest item that was achieved. Since Portuguese norms for this instrument are not yet available, age-adjusted residuals for the raw scores were computed and used in the statistical analyses.

Children's social competence and behaviour. At T2, teachers were asked to complete the Portuguese version of the Social Competence and Behaviour Evaluation Scale (SCBE-30; LaFreniere \& Dumas, 1996; Portuguese version, Santos \& Veríssimo, 2008), which aims to assess children's social competence and aggressive behaviour. This version consists of 30 items, in which teachers are invited to rate the frequency of several children's behaviours on a 6-point Likert scale, ranging from 1 ("Never") to 7 ("Always"). There is also an option for "Cannot assess" behaviours (N). These items are 
Running Head: SOCIAL UNDERSTANDING AND LATER SOCIAL COMPETENCE

arranged in three subscales of 10 items each. The Anger-Aggression subscale describes children's oppositional and aggressive behaviours; the Anxiety-Withdrawal subscale reflects children's anxious, withdrawn and dependent behaviours; finally, the Social Competence subscale describes children's positive and adaptive behaviours, reflecting social flexibility and emotional maturity. Cronbach's Alphas for the Portuguese version were .75 (Anger-Aggression), .73 (Anxiety-Withdrawal) and .73 (Social Competence).

\section{Analysis strategy}

We first performed preliminary analyses concerning children's ToM and mental state references at $\mathrm{T} 1$ and social competence and behaviour at T2, and their subsequent associations with the control variables, including mothers' education level, total number of words and mental references used by the mother during shared book-reading interactions; and children's age and verbal ability. Next, we carried out the correlational analyses addressing our two main aims: first, we examined the concurrent associations between children's ToM and mental state references at T1, and we subsequently investigated the longitudinal relationships between children's ToM and mental state references at T1 and children's social competence and behaviour later in life. Finally, we examined gender differences and performed correlations to investigate the associations between children's ToM and mental references at T1 and social competence at T2 separately by gender.

Given that the analysed variables did not meet the assumptions for parametric statistical analysis, non-parametric statistics were used.

\section{Results}

\section{Descriptive statistics and preliminary analyses}


Running Head: SOCIAL UNDERSTANDING AND LATER SOCIAL COMPETENCE

Table 1 presents the descriptive measures regarding children's mental state references, ToM, verbal ability scores and social competence and behaviour. Regarding mental references, mothers seemed to make more references to cognitions followed by emotions and desires. Children spoke notably less and made few references to mental states. A Friedman test followed by three Wilcoxon tests with Bonferroni correction showed no significant differences between the three types of mental references that were made, $\chi^{2}(2)=.20, p=.92$. Regarding ToM, all children succeeded in at least one of the tasks. The majority of the children were successful on the first three out of six individual ToM tasks, with 38 children (52.8\%) responding correctly in the Diverse Beliefs task, 64 (88.9\%) children responding correctly in the Knowledge Access task and 37 children (51.4\%) responding correctly in the Contents False Belief task. Regarding the remaining three tasks, the number of successful children decreased for the Explicit False Belief task, with 30 children (41.7\%) responding correctly, increasing for the Unexpected Contents II task, with 53 children (75.7\%) responding correctly, and decreasing again for the Unexpected Location task, where only 24 children (33.3\%) were successful.

----Insert Table 1 around here----

The correlations between children's ToM, mental state references and social competence and behaviour and the control variables are presented in Table 2.

Children's ToM was not significantly related to mothers' education level, children's age or verbal ability; however, ToM was significantly related to mothers' 
Running Head: SOCIAL UNDERSTANDING AND LATER SOCIAL COMPETENCE

references to mental states during the book-reading interactions, in that mothers who made more mental references had children who evidenced better ToM abilities.

We found no significant association between children's mental references and mothers' education level. However, when we examined the associations with mothers' discourse during the dyadic interaction, we found significant relationships between the total number of words used by the mother and the children's references to cognitions. Children whose mothers used more words during their interaction made more references to cognition terms. However, the mothers' and the children's use of mental references were not related. Regarding children's characteristics, we only found a significant association between children's age and references to emotions, showing that older children made more references to emotions. We found no significant associations with children's verbal ability.

Concerning children's social competence and behaviour that was assessed at T2, children's anxiety-withdrawal reports were significantly negatively associated with mothers' education level. Therefore, children whose mothers had higher education qualifications were rated by their teachers as showing less anxiety-withdrawal behaviour. Conversely, children's aggressive behaviour and social competence were not related to mothers' education level. In addition, no associations were found with children's variables, such as age and verbal ability.

----Insert Table 2 around here----

Since children's age, mothers' education level and mothers' total number of words and mental references used during the shared book-reading interaction were significantly associated with children's mental references, ToM and social competence 
Running Head: SOCIAL UNDERSTANDING AND LATER SOCIAL COMPETENCE

and behaviour, we controlled for these variables in the subsequent analyses. Moreover, considering that children's verbal ability is a well-known correlate of ToM (Milligan, Astington, \& Dack, 2007), we also controlled for this variable, despite its not being significantly associated with any of our main variables.

\section{Association between children's ToM and mental references.}

We found a significant positive association between children's ToM abilities and their use of cognition terms, $r_{s}=.25, p=.036$. Therefore, children who displayed a better ToM used more cognition references when interacting with their mothers. Conversely, we found no significant associations between children's ToM skills and their references to desires, emotions or to mental states in general, $r_{s}=-.01, p=.95, r_{s}=$ $-.19, p=.11$ and $r_{s}=.07, p=.58$, respectively.

Furthermore, after controlling for children's age at the time of the assessment, their verbal ability, the mothers' total number of words and the proportion of mental references during the shared book-reading, the pattern of results was the same, with children's ToM being associated only with children's references to cognitions, $r_{s}(66)=$ $.29, p=.016$

\section{Association between children's social understanding and later social} competence and behaviour.

We found no significant associations between children's ToM or mental references, and the social competence and behaviour subscales, although the relationships between children's references to cognitions and desires and their later 
anger-aggression scores was close to statistical significance $(p=.051$ and $p=.063$, respectively).

\section{Gender differences in children's ToM, mental references and social competence} and behaviour.

Next, we examined gender differences concerning our main variables (Table 3) and found no significant differences between genders, concerning both their performance on the ToM tasks and their use of mental states during interactions with their mothers.

However, concerning children's social competence and behaviour, we did find significant gender differences, specifically regarding the anxiety-withdrawal scale, $Z=-$ $4.09, p<.001$. Thus, teachers reported that girls showed more anxious-withdrawn behaviour compared to boys. We found no gender differences regarding the angeraggression and social competence subscales, $Z=-1.72, p=.09$ and $Z=-1.27, p=.21$, respectively.

----Insert Table 3 around here----

\section{Association between children's social understanding and later social competence and behaviour by gender.}

Finally, we investigated the association between children's ToM abilities and mental references at $\mathrm{T} 1$ and their social competence and subsequent behaviour at $\mathrm{T} 2$ separately by gender (Table 4). 
Running Head: SOCIAL UNDERSTANDING AND LATER SOCIAL COMPETENCE

----Insert Table 4 around here----

Regarding ToM, we found a significant association between ToM and social competence and behaviour but only in girls. Therefore, girls who performed better on the ToM tasks were rated by their teachers as showing less aggressive behaviour, $r_{s}=-$ $.45, p=.012$, and shy/withdrawn behaviour, $r_{s}=-.40, p=.029$, and showed more social competence, $r_{s}=.38, p=.040$ one year later. After controlling for girls' age, verbal ability, their mothers' education level, and total number of words and mental references used during the shared book-reading interaction, the relationship between ToM and later ratings regarding shy/withdrawn behaviour remained significant, $r_{s}(23)=-.49, p=.013$. However, the association between girls' ToM and later scores concerning aggressive behaviour and social competence were rendered not significant, $r_{s}(23)=-.26, p=.22$ and $r_{s}(23)=.37, p=.068$, respectively. Similarly, there was a relationship between children's use of mental references and later social competence and behaviour only in girls. Thus, girls who referred more to desires at $4 \frac{1}{2} 2$ years of age were rated by their teachers as showing more aggressive behaviour later on, $r_{s}=.36, p=.049$. Conversely, girls who made more references to cognitions at age $4 \frac{1}{2}$ were rated by their teachers as displaying less aggressive behaviour one year later, $r_{s}=-.36, p=.046$. We found no significant relationship between children's references to emotions and the social competence and behaviour subscales. When controlling for girls' age, verbal ability, their mothers' education level, and the total number of words and mental state references used during their interaction, a significant association emerged between children's references to cognition terms and their scores on the social competence subscale, $r_{s}(23)=.45, p=.023$. Conversely, the links between children's references to 
Running Head: SOCIAL UNDERSTANDING AND LATER SOCIAL COMPETENCE

desires and cognitions and the aggressive behaviour subscale became not significant, $r_{s}$ $(23)=.28, p=.17$ and $r_{s}(23)=-.39, p=.053$, respectively.

Next, using Fisher's r-to-z transformation, we compared the strength of the correlations between girls' ToM and mental state talk, and between boys' ToM and mental state talk, with their later social competence and behaviour. We found significant differences between ToM in girls' and ToM in boys' and the teacher's ratings regarding aggressive behaviour, $\mathrm{Z}=2.40, p=.017$, and overall social competence, $\mathrm{Z}=-2.36, p=$ .018 , which showed that the correlation coefficient between ToM and social competence and behaviour was larger for girls than for boys. Gender differences concerning the relationship between children's ToM and anxiety withdrawal were not significant, despite almost reaching significance, $\mathrm{Z}=1.84, p=.066$. No significant differences were found between girls' and boys' correlations between ToM and mental state references and social competence and behaviour ( $p>.30$ for all).

\section{Discussion}

Our first primary goal was to investigate the concurrent relationship between children's ToM and use of mental state references. We observed associations between children's ToM abilities and children's tendency to refer to mental states, specifically cognitions. Children who performed better on the ToM tasks also used more cognitionrelated terms during a shared book-reading interaction with their mothers, even after controlling for children's age, verbal ability and their mothers' discourse during their interactions. This corroborates previous findings (e.g., Ensor \& Hughes, 2008; Nielsen \& Dissanayake, 2000; Ruffman et al., 2006), suggesting that children who perform better on a standardized battery of ToM tasks, also display a better understanding of the mind in real-life interactions with others by focusing and referring more frequently to 
mental states in their discourse. Furthermore, it seems that this link is specific to children's references to cognitions, as we did not identify any associations with children's references to other mental states, such as desires or emotions, or to mental states in general. It is important to note that the battery of ToM tasks that was used in this study was composed solely of cognition-related tasks; thus, the measures were mainly oriented towards the assessment of false belief understanding. Additionally, as cognitions are considered to be the most complex and advanced type of mental states, being truly representational (Bartsch \&Wellman, 1995), this relationship does not come as a surprise. It is possible that children who performed better on these cognition-related tasks focused more on the cognitive states of the characters in the story, and therefore referred more often to cognitions.

Our results might also have been influenced by the social partner that the child was interacting with. This would be consistent with previous findings that showed that children use more mental references when interacting with friends and siblings than with their mothers (Brown \& Dunn, 1992; Brown et al., 1996; Hughes, Marks, Ensor, \& Lecce, 2010), leading some authors to argue that children's social understanding is relationship-specific (Hughes \& Dunn, 2002; Hughes et al., 2007, 2010). Therefore, children might apply their understanding of the mind differently in different relationships (Hughes, 2011). Concerning our study, it is possible that because these shared book-reading interactions were mostly guided by the mother, children were not as spontaneous as they would be when talking with a sibling or a friend, and they ended up talking less and using fewer references to mental states. Still, it is noteworthy that our results held up even after controlling for the mothers' discourse. Another possibility is that the relationship between the children's performance on standardized ToM tasks and the children's tendency to refer to mental states during their daily interactions is 
reflective of the role of other individual characteristics, such as the children's temperament. It is possible that, for example, children who are more extroverted tend to talk more when interacting with others, and thus use more mental state references as compared to more introverted children. Further investigation is warranted to examine these hypotheses.

Our second aim was to examine the longitudinal associations between preschool children's social understanding, indexed by their ToM and use of mental references, and their social competence and behaviour later in life. We found no associations between children's ToM abilities and teacher ratings of their social competence and behaviour one year later; however, when we examined these analyses by gender, we found that ToM was related to social competence and behaviour in girls. Specifically, after controlling for children's age, verbal ability, their mothers' education level and discourse during the shared book-reading interactions, girls who performed better on the ToM tasks were rated by their teachers as showing less shy/withdrawn behaviour. These results corroborate and expand on previous research (Razza \& Blair, 2003; Walker, 2005), which observed that relationships between children's ToM and social competence differed by gender and reported concurrent associations between ToM and socially competent and prosocial behaviours in girls. Even though we also found gender differences regarding children's shy/withdrawn behaviour, with girls being rated by their teachers as showing more of this type of behaviour, we found no gender differences concerning aggressive behaviour and the social competence subscale or ToM, which makes these results more interesting. Moreover, only the correlation coefficients between ToM and aggressive behaviour and the social competence subscale in girls were larger than that of boys, as compared using Fisher's r-to-z transformation, providing further support to our findings. Thus, it is possible that girls and boys differ as 
to how they use their ToM abilities in their everyday life and interactions with others (Razza \& Blair, 2003; Walker, 2005). It is also possible, as Walker (2005) noted, that gender-specific styles of social interaction play a role in explaining this association between ToM and social competence and behaviour. In fact, several studies have provided evidence pointing out gender differences in terms of social behaviour and patterns of interaction with others. Thus, girls seem to present with more prosocial behaviour and higher levels of play interaction (Coolahan, Fantuzzo, Mendez, \&McDermott, 2000; Palermo, Hanish, Martin, Fabes, \& Reiser, 2007), and show more conflict resolution and emphatic understanding in their relationships (Rose \& Asher, 1999; Rose \& Rudolph, 2006). Conversely, boys appear prone to more aggressive behaviour and are more likely to take part in more physical, disconnected and disruptive types of play (Coolahan et al., 2000; Moller, Hymel, \& Rubin, 1992; Palermo et al., 2007). A recent meta-analysis is also in support of these findings, and showed that the link between children's ToM and peer popularity was stronger for girls than for boys (Slaughter, Imuta, Peterson, \& Henry, 2015). Thus, it is possible that girls utilize their ToM abilities to engage in more prosocial behaviour, favouring the development of better social relationships with their peers and teachers, while boys use their ToM in distinct ways. This idea is also congruent with prior suggestions that girls are more “interpersonally oriented” than boys (Banerjee, Rieffe, Terwogt, Gerlein, \& Voutsina, 2006; Crick \& Dodge, 1994). Interestingly, and also following this line, prior research has provided evidence supporting the idea that ToM is not always related to social competence and positive behaviours, as bullies have been found to have superior ToM skills, using these competencies for manipulative behaviours (e.g., Sutton, Smith, \& Swettenham, 1999). 
Our results, along with previous studies, suggest that it may be important to consider gender-specific effects when investigating children's social understanding and its relationship with other social-emotional outcomes. To the best of our knowledge, our study is the first to show longitudinal, gender-specific associations between preschool children's ToM and their social competence assessed approximately one year later. This longitudinal design expands on previous cross-sectional studies and makes it possible to induce potential causal relationships, thus giving support to the idea that it is girls' ToM at $4 \frac{1}{2}$ years of age that promotes their social competence and behaviour approximately one year later. However, it is important to note that since we did not assess children's social competence and behaviour at $4 \frac{1}{2} 2$ years of age, it remains unclear whether ToM at T1 is promoting children's social competence and behaviour at T2 or whether our results merely reflect the associations between children's ToM and social competence and behaviour across time. This issue is an important aspect for future consideration in research.

It is also interesting to note that when we analysed the associations between children's mental references and their later social competence and behaviour by gender, our results were similar to the ones we found regarding ToM. After accounting for the same control variables, girls who used more references to cognitions during interactions with their mothers were rated by their teachers one year later as displaying more social competence. These results are also consistent with the idea mentioned above that it may be relevant to take into account gender-specific effects when investigating children's social understanding.

Interestingly, our results differ from those reported by Longobardi and colleagues (Longobardi et al., 2015) in the first study to examine the association between children's ToM and mental state talk simultaneously with social adjustment. 
While our findings show associations between preschoolers' ToM and mental references, specifically cognitions, and similar patterns of relationships from both indices of girls' social understanding and later social competence and behaviour, Longobardi et al. found no associations between school-aged children's ToM and mental state talk, and only the latter was related to measures of social adjustment. This discrepancy could have to do with the children's age, as other studies have also failed to find an association between older children's ToM and mental references (e.g., Meins et al., 2006). It could be that during preschool years, when children are typically developing and consolidating their ToM abilities, they rely more on these growing abilities during daily interactions, for example in discussing mental states. However, as children grow older and these socio-cognitive abilities mature, the use of mental references becomes independent from general ToM abilities, an idea that was already put forth in prior research (Meins et al., 2006).

Several methodological issues should be taken into account when interpreting our findings. It is important to note that in the shared book-reading task, mothers were instructed to tell the story to their children, thereby guiding the interaction. Therefore, since children talked notably less, they might also have made fewer mental references. Accordingly, we found that children whose mothers talked more, using more words during the story-telling, referred more to cognition terms during that same interaction. Thus, it is possible that their mothers' speech influenced the children's performance and correlated with some other factors related to the child's social competence later in life. Indeed, mothers who talk more can direct their interventions to stimulate their children to think about and talk more about mental states, particularly cognitions. Therefore, mothers may be scaffolding their children's understanding of the mind, which is consistent with existing literature showing the crucial role that parents have in 
promoting their children's social understanding (Meins et al., 2013; Ruffman et al., 1999, 2002, 2006; Symons et al., 2005). Similarly, our findings showed that children whose mothers referred more to mental states during their interactions had a better performance on ToM tasks, and when we controlled for these mothers' mental references, the total number of words used, the mothers' education level and the children's age and verbal ability, the associations between children's ToM and later ratings regarding aggressive behaviour and social competence were weakened. In addition, it is important to note that in our study, children's social competence and behaviour were assessed only from the perspective of the teacher using a questionnaire. It would be important for future studies to include more than one informant in order to get a more complete perspective on the children's competencies and behaviour. Additionally, it would be interesting to explore the pattern of results obtained using observational measures of children's social competence and behaviour. It is also important to mention that while the application of the individual ToM tasks was counterbalanced, it was not possible to test for order effects aside from the first two fixed tasks, which is another aspect that would be important to consider in future studies.

To the best of our knowledge, this study is the first to examine the longitudinal association between two indices of preschool children's social understanding - ToM and mental references - and their social competence. Our findings show for the first time that children's performance on a standardized battery of ToM tasks is not only related to children's references to mental states, specifically cognitions, during motherchild interactions but also that the two are related to children's reported social behaviour one year later and only in girls. Our findings show that in girls but not boys, ToM and mental references were related to later social competence, which highlights the 
Running Head: SOCIAL UNDERSTANDING AND LATER SOCIAL COMPETENCE

importance of further exploration of gender-specific effects when studying children's social cognition; this finding is in line with previous suggestions that boys and girls may differ in how they use their socio-cognitive abilities in their real-life interactions (Razza \& Blair, 2003; Walker, 2005). Moreover, the fact that we found an association between children's ToM and mental references and that both ToM and mental state talk showed a similar longitudinal pattern of gender-specific results in relation to later social competence and behaviour, brings further support to the idea that we are talking about two important indices of children's social understanding, which are similarly reflected in children's later social competence and behaviour. Therefore, it would be interesting for future studies to continue to explore these associations, thereby bridging the gap between using experimental and naturalistic paradigms in assessing children's understanding of the mind while examining the relationships between this wider view of children's social understanding and other outcomes in children. 


\section{References}

Astington, J. W., \& Barriault, T. (2001). Children's theory of mind: how young children come to understand that people have thoughts and feelings. Infants and young children, 13(3), $1-12$.

Astington, J. W., \& Jenkins, J. M. (1999). A longitudinal study of the relation between language and theory-of-mind understanding. Developmental Psychology, 35(5), 13111320. doi: 10.1037/0012-1649.35.5.1311

Banerjee, R., Rieffe, C., Terwogt, M. M., Gerlein, A. M., \& Voutsina, M. (2006). Popular and rejected children's reasoning regarding negative emotions in social situations: The role of gender. Social Development, 15(3), 418-433. doi: 10.1111/j.1467-9507.2006.00349.x

Bartsch, K., \& Wellman, H. M. (1995). Children talk about the mind. Oxford, UK: Oxford University Press.

Bretherton, I., \& Beeghly, M. (1982). Talking about internal states: The acquisition of an explicit theory of mind. Developmental Psychology, 18(6), 906-921. doi: 10.1037/00121649.18.6.906

Brown, J. R., Donelan-McCall, N., \& Dunn, J. (1996). Why talk about mental states? The significance of children's conversations with friends, siblings, and mothers. Child Development, 67(3), 836-849. doi: 10.1111/j.1467-8624.1996.tb01767.x 
Running Head: SOCIAL UNDERSTANDING AND LATER SOCIAL COMPETENCE

Brown, J. R., \& Dunn, J. (1992). Talk with your mother or your sibling? Developmental changes in early family conversations about feelings. Child Development, 63(2), 336349. doi: 10.1111/j.1467-8624.1992.tb01631.x

Carpendale, J. I. M., \& Lewis, C. (2004). Constructing an understanding of mind: The development of children's social understanding within social interaction. Behavioural and Brain Sciences, 27(1), 79-151. doi: 10.1017/S0140525X04000032

Capage, L., \& Watson, A. C. (2001). Individual differences in theory of mind, aggressive behaviour, and social skills in young children. Early Education and Development, 12(4), 613-628. doi: 10.1207/s15566935eed1204_7

Coolahan, K., Fantuzzo, J., Mendez, J., \& McDermott, P. (2000). Preschool peer interactions and readiness to learn: Relationships between classroom peer play and learning behaviours and conduct. Journal of Educational Psychology, 92(3), 458-465. doi: $10.1037 / 0022-0663.92 .3 .458$

Crick, N. R., \& Dodge, K. A. (1994). A review and reformulation of social information processing mechanisms in children's social adjustment. Psychological Bulletin, 115(1), 74-101. doi: 10.1037/0033-2909.115.1.74

Dunn, J. (1988). The beginnings of social understanding. Cambridge, MA: Harvard University Press.

Dunn, J. (1991). Young children's understanding of other people: Evidence from observations within the family. In C. Moore \& D. Frye (Eds.), Children's theory of mind: Mental states and social understanding (pp. 97-114). New York: Lawrence Erlbaum Associates, Inc.

Dunn, L. M., \& Dunn, L.M. (1981). Peabody Picture Vocabulary Test-Revised: Form M. Circle Pines, MN: American Guidance Service. 
Running Head: SOCIAL UNDERSTANDING AND LATER SOCIAL COMPETENCE

Ensor, R., \& Hughes, C. (2008). Content or connectedness? Mother-child talk and early social understanding. Child Development, 79(1), 201-216. doi: 10.1111/j.14678624.2007.01120.x

Garner, P. W., Curenton, S. M., \& Taylor, K. (2005). Predictors of mental state understanding in preschoolers of varying socioeconomic backgrounds. International Journal of Behavioural Development, 29(4), 271-281. doi: 10.1080/01650250544000053

Garner, P. W., Dunsmore, J. C., \& Southam-Gerrow, M. (2008). Mother-child conversations about emotions: Linkages to child aggression and prosocial behaviour. Social Development, 17(2), 259-277. doi: 10.1111/j.1467-9507.2007.00424.x

Hughes, C. (2011). Social understanding and social lives: From toddlerhood through the transition to school. London, UK: Psychology Press

Hughes, C., Adlam, A., Happé, F., Jackson, J., Taylor, A., \& Caspi, A. (2000). Good test-retest reliability for standard and advanced false-belief tasks across a wide range of abilities. Journal of Child Psychology and Psychiatry, 41(4), 483-490. doi: 10.1111/14697610.00633

Hughes, C., \& Dunn, J. (1998). Understanding mind and emotion: Longitudinal associations with mental-state talk between young friends. Developmental Psychology, 34(5), 10261037. doi: 10.1037/0012-1649.34.5.1026

Hughes, C., \& Dunn, J. (2002). "When I say a naughty word.” A longitudinal study of young children's accounts of anger and sadness in themselves and close others. British Journal of Developmental Psychology, 20(4), 515-535. doi: 10.1348/026151002760390837

Hughes, C., Deater-Deckard, K., \& Cutting, A. L. (1999). "Speak roughly to your little boy?" Sex differences in the relations between parenting and preschoolers' understanding of mind. Social Development, 8(2), 143-160. doi: 10.1111/1467-9507.00088 
Running Head: SOCIAL UNDERSTANDING AND LATER SOCIAL COMPETENCE

Hughes, C., Ensor, R., \& Marks, A. (2011). Individual differences in false belief understanding are stable from 3 to 6 years of age and predict children's mental state talk with school friends. Journal of Experimental Child Psychology, 108(1), 96-112. doi:

10.1016/j.jecp.2010.07.012

Hughes, C., Lecce, S., \& Wilson, C. (2007). “Do you know what I want?” Preschoolers' talk about desires, thoughts and feelings in their conversations with sibs and friends. Cognition and Emotion, 21(2), 330-350. doi: 10.1080/02699930600551691

Hughes, C., Marks, A., Ensor, R., \& Lecce, S. (2010). A longitudinal study of conflict and inner state talk in children's conversations with mothers and younger siblings. Social Development, 19(4), 822-837. doi: 10.1111/j.1467-9507.2009.00561.x

Jenkins, J. M., Turrell, S. L., Kogushi, Y., Lollis, S., \& Ross, H. S. (2003). A longitudinal investigation of the dynamics of mental state talk in families. Child Development, 74(3), 905-920. doi: 10.1111/1467-8624.00575

LaFreniere, P. J., \& Dumas, J. E. (1996). Social competence and behaviour evaluation in children ages 3 to 6 years: the short form (SCBE-30). Psychological Assessment, 8(4), 369-377. doi: 10.1037/1040-3590.8.4.369

Lalonde, C. E., \& Chandler, M. J. (1995). False belief understanding goes to school: On the social-emotional consequences of coming early or late to a first theory of mind. Cognition and Emotion, 9(2/3), 167-185. doi: 10.1080/02699939508409007

Longobardi, E., Spataro, P., \& Rossi-Arnaud, C. (2015). Relations between theory of mind, mental state language and social adjustment in primary school children. European Journal of Developmental Psychology. Advance online publication. doi: $10.1080 / 17405629.2015 .1093930$

Mayer, M. (1969). Frog, where are you? New York: Dial Press.

Mayer, M. (1992). Frog on his own. New York: Puffin. 
Running Head: SOCIAL UNDERSTANDING AND LATER SOCIAL COMPETENCE

McAlister, A., \& Peterson, C. C. (2007). A longitudinal study of siblings and theory of mind development. Cognitive Development, 22(2), 258-270. doi:

10.1016/j.cogdev.2006.10.009

Meins, E., Fernyhough, C., Arnott, B., Leekam, S. R., \& de Rosnay, M. (2013). Mindmindedness and theory of mind: Mediating roles of language and perspectival symbolic play. Child Development, 84(5), 1777-1790. doi: 10.1111/cdev.12061

Meins, E., Fernyhough, C., Johnson, F., \& Lidstone, J. (2006). Mind-mindedness in children: Individual differences in internal-state talk in middle childhood. British Journal of Developmental Psychology, 24(1), 181-196. doi: 10.1348/026151005X80174

Meins, E., Fernyhough, C., Wainwright, R., Das Gupta, M., Fradley, E., \& Tuckey, M. (2002). Maternal mind-mindedness and attachment security as predictors of theory of mind understanding. Child Development, 73(6), 1715-1726. doi: 10.1111/1467-8624.00501

Milligan, K., Astington, J. W., \& Dack, L. A. (2007). Language and theory of mind: Metaanalysis of the relation between language ability and false-belief understanding. Child Development, 78(2), 622-646. doi: 10.1111/j.1467-8624.2007.01018.x

Moller, L. C., Hymel, S., \& Rubin, K. H. (1992). Sex typing in play and popularity in middle childhood. Sex Roles, 26(7-8), 331-353. doi: 10.1007/BF00289916

Nielsen, M., \& Dissanayake, C. (2000). An investigation of pretend play, mental state terms and false belief understanding: In search of a metarepresentational link. British Journal of Developmental Psychology, 18(4), 609-624. doi: 10.1348/026151000165887

Osório, A., Meins, E., Martins, C., Martins, E. C., \& Soares, I. (2012). Child and mother mental-state talk in shared pretense as predictors of children's social symbolic play abilities at age 3. Infant Behaviour and Development, 35(4), 719-726. doi:

10.1016/j.infbeh.2012.07.012 
Running Head: SOCIAL UNDERSTANDING AND LATER SOCIAL COMPETENCE

Palermo, F., Hanish, L. D., Martin, C. L., Fabes, R. A., \& Reiser, M. (2007). Preschoolers academic readiness: What role does the teacher-child relationship play? Early Childhood Research Quarterly, 22(4), 407-422. doi: 10.1016/j.ecresq.2007.04.002

Razza, R. P., \& Blair, C. (2003). False-belief understanding in a low-income population. Early Education and Development, 14(4), 425-440. doi: 10.1207/s15566935eed1404_3

Razza, R. A., \& Blair, C. (2009). Associations among false-belief understanding, executive function, and social competence: A longitudinal analysis. Journal of Applied Developmental Psychology, 30(3), 332- 343. doi: 10.1016/j.appdev.2008.12.020

Repacholi, B., \& Trapolini, T. (2004). Attachment and preschool children's understanding of maternal versus non-maternal psychological states. British Journal of Developmental Psychology, 22(3), 195-415. doi: 10.1348/0261510041552693

Rose, A. J., \& Asher, S. R. (1999). Children's goals and strategies in response to conflicts within a friendship. Developmental Psychology, 35(1), 69-79. Doi: 10.1037/00121649.35.1.69

Rose, A. J., \& Rudolph, K. D. (2006). A review of sex differences in peer relationship processes: Potential trade-offs for the emotional and behavioural development of girls and boys. Psychological Bulletin,132(1), 98-131. Doi: 10.1037/0033-2909.132.1.98

Ruffman, T., Perner, J., \& Parkin, L. (1999). How parenting style affects false belief understanding. Social Development, 8(3), 395-411. doi: 10.1111/1467-9507.00103

Ruffman, T., Slade, L., \& Crowe, E. (2002). The relation between children's and mothers' mental state language and theory-of-mind understanding. Child Development, 73(3), 734-751. doi: 10.1111/1467-8624.00435

Ruffman, T., Slade, L., Devitt, K., \& Crowe, E. (2006). What mothers say and what they do: The relation between parenting, theory of mind, language and conflict/cooperation. 
Running Head: SOCIAL UNDERSTANDING AND LATER SOCIAL COMPETENCE

British Journal of Developmental Psychology, 24(1), 105-124. doi:

$10.1348 / 026151005 \times 82848$

Santos, A., \& Veríssimo, M. (2008). Escala de avaliação do comportamento e competência social (LaFreniere \& Dumas, 1995). In XIII Conferência Internacional Avaliação Psicológica: Formas e contextos, Braga, Portugal.

Slaughter, V., Imuta, K., Peterson, C. C., \& Henry, J. D. (2015). Meta-analysis of theory of mind and peer popularity in the preschool and early school years. Child Development, 86(4), 1159-1174. doi: 10.1111/cdev.12372

Sutton, J., Smith, P. K., \& Swettenham, J. (1999). Social cognition and bullying: Social inadequacy or skilled manipulation? British Journal of Developmental Psychology, 17(3), 435-450. doi: 10.1348/026151099165384

Symons, D. K. (2004). Mental state discourse, theory of mind, and the internalization of selfother understanding. Developmental Review, 24(2), 159-188. doi:

10.1016/j.dr.2004.03.001

Symons, D. K., \& Clark, S. E. (2000). A longitudinal study of mother-child relationships and theory of mind in the preschool period. Social Development, 9(1), 3-23. doi: $10.1111 / 1467-9507.00108$

Symons, D. K., Peterson, C. C., Slaughter, V., Roche, J., \& Doyle, E. (2005). Theory of mind and mental state discourse during book reading and story-telling tasks. British Journal of Developmental Psychology, 23(1), 81-102. doi: 10.1348/026151004X21080

Taumoepeau, M., \& Ruffman, T. (2006). Mother and infant talk about mental states relates to desire language and emotion understanding. Child Development, 77(2), 465-481. doi: 10.1111/j.1467-8624.2006.00882.x 
Running Head: SOCIAL UNDERSTANDING AND LATER SOCIAL COMPETENCE

Walker, S. (2005). Gender differences in the relationship between young children's peer-related social competence and individual differences in theory of mind. The Journal of Genetic Psychology, 166(3), 297-312. doi: 10.3200/GNTP.166.3.297-312

Weimer, A. A., \& Guajardo, N. R. (2005). False belief, emotion understanding, and social skills among head start and non-head start children. Early Education and Development, 16(3), 341-366. doi: 10.1207/s15566935eed1603_3

Wellman, H. M., Cross, D., \& Watson, J. (2001). Meta-analysis of theory of mind development: The truth about false belief. Child Development, 72(3), 655-684. doi: $10.1111 / 1467-8624.00304$

Wellman, H. M., \& Liu, D. (2004). Scaling of theory-of-mind tasks. Child Development, 75(2), 523-541. doi: 10.1111/j.1467-8624.2004.00691.x 
Table 1. Descriptive statistics regarding children's mental state references, ToM, verbal ability and later social competence and behaviour

\begin{tabular}{lcc}
\hline & Mean (S.D) & Range \\
\hline $\begin{array}{l}\text { Mothers' Mental state references } \\
\text { Total number of words }\end{array}$ & \\
Proportion of mental references & $0.022(0.51(320.87)$ & $401-2236$ \\
Proportion of desire references & $0.003(0.002)$ & $0.01-0.04$ \\
Proportion of cognition references & $0.010(0.005)$ & $0.00-0.01$ \\
Proportion of emotion references & $0.009(0.004)$ & $0.00-0.02$ \\
Children's Mental state references & & \\
Total number of words & $86.52(73.44)$ & $2-433$ \\
Proportion of mental references & $0.015(0.020)$ & $0.00-0.12$ \\
Proportion of desire references & $0.005(0.011)$ & $0.00-0.06$ \\
Proportion of cognition references & $0.005(0.008)$ & $0.00-0.04$ \\
Proportion of emotion references & $0.005(0.015)$ & $0.00-0.12$ \\
Children's ToM & $3.42(1.53)$ & $1-6$ \\
Children's Verbal ability & $91.26(19.95)$ & $46-126$ \\
Children's Social Competence and & & $1.00-3.78$ \\
Behaviour & & $1.00-2.80$ \\
Anger-Aggression & $4.42(0.98)$ & \\
Social Competence & & \\
\hline & & \\
\hline
\end{tabular}


Table 2. The relation between children's mental state references, ToM, and later social competence and behaviour and mothers' and children's control variables

\begin{tabular}{|c|c|c|c|c|c|}
\hline & \multicolumn{3}{|c|}{ Mothers' variables } & \multirow{2}{*}{$\begin{array}{c}\begin{array}{c}\text { Children's } \\
\text { variables }\end{array} \\
\text { Age }\end{array}$} & \multirow[b]{2}{*}{$\begin{array}{l}\text { Verbal } \\
\text { ability }\end{array}$} \\
\hline & $\begin{array}{l}\text { Education } \\
\text { level }\end{array}$ & $\begin{array}{c}\text { Total } \\
\text { number } \\
\text { of words }\end{array}$ & $\begin{array}{c}\text { Total } \\
\text { mental } \\
\text { references }\end{array}$ & & \\
\hline Children's ToM (T1) & .06 & -.05 & $.24^{*}$ & -.02 & .13 \\
\hline \multicolumn{6}{|l|}{$\begin{array}{l}\text { Children's Mental } \\
\text { references (T1) }\end{array}$} \\
\hline Total mental references & -.07 & .18 & -.01 & .03 & .00 \\
\hline Desires & -.12 & .20 & -.04 & -.05 & -.09 \\
\hline Cognitions & .09 & $.25^{*}$ & -.04 & .03 & .06 \\
\hline Emotions & -.15 & .12 & .00 & $.23^{*}$ & -.02 \\
\hline \multicolumn{6}{|l|}{$\begin{array}{l}\text { Social competence } \\
\text { and behaviour (T2) }\end{array}$} \\
\hline Anger-aggression & $-.30^{*}$ & -.04 & -.09 & .13 & -.13 \\
\hline Anxiety-withdrawal & $-.28^{*}$ & .05 & .11 & -.09 & .07 \\
\hline Social competence & -.00 & -.14 & -.01 & -.07 & -.01 \\
\hline
\end{tabular}

${ }^{*} p<.05 ;$ Spearman Correlation Coefficient 
Table 3. Gender differences regarding children's ToM, mental state talk and social competence and behaviour

\begin{tabular}{|c|c|c|c|}
\hline & $\begin{array}{c}\text { Boys } \\
(n=38) \\
\operatorname{Mean}(S . D)\end{array}$ & $\begin{array}{c}\text { Girls } \\
(n=35) \\
\text { Mean }(S . D)\end{array}$ & $Z$ \\
\hline ToM & $3.32(1.47)$ & $3.53(1.60)$ & -.53 \\
\hline
\end{tabular}

Mental references

Total mental references

$\begin{array}{lll}1.32(2.30) & 1.60(1.87) & -.41 \\ 0.53(1.16) & 0.43(0.66) & -.11 \\ 0.47(1.18) & 0.66(1.08) & -.72 \\ 0.32(0.57) & 0.51(1.01) & -.54\end{array}$

Desires

Cognitions

$0.32(0.57)$ $-54$

Social competence and behaviour

Anger-Aggression $1.46(0.57) \quad 1.31(0.44) \quad-1.72$

Anxiety-Withdrawal $1.20(0.21) \quad 1.66(0.53) \quad \mathbf{- 4 . 0 9} 9^{* * * *}$

Social Competence

$4.30(0.95)$

$4.56(1.02)$

$-1.27$

Note: Although we report the results from Mann-Whitney tests, carried out with the proportions of children's mental references, for the purpose of data intelligibility, we present the means and standard deviations of the original raw variables.

**** $p<.01$ 
Table 4. Full/partial correlations between children's mental state references, ToM, and later social competence and behaviour, by gender

Social competence and behaviour

\begin{tabular}{|c|c|c|c|}
\hline & Anger-Aggression & $\begin{array}{c}\text { Anxiety } \\
\text { withdrawal }\end{array}$ & $\begin{array}{c}\text { Social } \\
\text { competence }\end{array}$ \\
\hline \multicolumn{4}{|c|}{ Children's ToM } \\
\hline Boys & $.14 / .08$ & $.06 / .03$ & $-.21 /-.23$ \\
\hline Girls & $-.45 * /-.26$ & $-.40 * /-.49 *$ & $.38 * / .37$ \\
\hline \multicolumn{4}{|c|}{ Children's Mental references } \\
\hline \multicolumn{4}{|c|}{ Total mental references } \\
\hline Boys & $-.04 /-.09$ & $-.18 /-.19$ & $.19 / .18$ \\
\hline Girls & $.03 / .05$ & $-.14 /-.30$ & $.12 / .29$ \\
\hline \multicolumn{4}{|l|}{ Desires } \\
\hline Boys & $.14 / .03$ & $-.08 /-.10$ & $.13 / .10$ \\
\hline Girls & $.36 * / .28$ & $.05 /-.07$ & $-.14 /-.09$ \\
\hline \multicolumn{4}{|l|}{ Cognitions } \\
\hline Boys & $-.12 /-.13$ & $-.21 /-.20$ & $.12 / .08$ \\
\hline Girls & $-.36 * /-.39$ & $-.09 /-.22$ & $.17 / .45^{*}$ \\
\hline \multicolumn{4}{|l|}{ Emotions } \\
\hline Boys & $-.10 /-.08$ & $-.19 /-.16$ & $.11 / .13$ \\
\hline Girls & $-.12 /-.13$ & $.05 /-.13$ & $.05 / .17$ \\
\hline
\end{tabular}

Note: Partial correlations, controlling for mothers' educational level, total number of words and proportion of mental references used during the book-reading interaction and children's age and verbal ability at T1.

${ }^{*} p<.05$; Spearman Correlation Coefficient 